\title{
Factors related to early mortality in cirrhotic patients bleeding from varices and treated by urgent sclerotherapy
}

O Le Moine, M Adler, N Bourgeois, M Delhaye, J Devière, M Gelin, A Vandermeeren, A Van Gossum, A Vereerstraeten, $P$ Vereerstraeten, $M$ Cremer

\begin{abstract}
Variceal haemorrhage in cirrhotic patients carries a high early mortality even when balloon tamponade or emergency sclerotherapy are applied. The aim of this study to identify patients dying within six weeks of their first variceal haemorrhage. One hundred and twenty one patients with parenchymal cirrhosis presenting with the first variceal bleeding episode between June 1983 and December 1988 were studied. Nineteen patients were excluded for various reasons. Emergency sclerotherapy was carried out in cases of active bleeding or where there were endoscopic signs of recent bleeding, and then regularly repeated afterwards. Of the 24 variables studied and included in a multivariate analysis using a logistic regression model, three had an independent prognostic value: encephalopathy, prothrombin time, and the number of blood units transfused within the 72 hours of time zero. The subsequent regression equation was able to predict $89 \%$ of the patients who will die and $97 \%$ of the patients who will still be alive six weeks after their first variceal haemorrhage treated by sclerotherapy. Pugh score was less discriminatory than these last three variables in terms of accuracy of adjustment, goodness of fit to the model, receiver operating characteristic curves, and percentage correct prediction. To measure the accuracy of the prediction rule, our model was applied to another series of 28 cirrhotic patients admitted with their first variceal bleeding during the next period (January 1989 to May 1990). Death and survival were correctly predicted in respectively $82 \%$ and $94 \%$ of the cases. The use of this score is recommended for the selection of patients with high early mortality after variceal bleeding despite sclerotherapy, and for the design of new therapeutic trials.

(Gut 1992; 33: 1381-1385)
\end{abstract}

Variceal haemorrhage in cirrhotic patients carries high early mortality ranging from $31 \cdot 6^{1}$ to $63.3 \%,{ }^{2}$ even when balloon tamponade, drugs or emergency sclerotherapy are used as first line treatment. Death is mainly because of exsanguination or liver failure. ${ }^{3}$ Studies assessing the value of various risk factors and scoring systems in patients with acute variceal haemorrhage are important as they may offer a useful mean of selection for entry into clinical trials or they may identify a group of patients with a very high mortality. Endoscopic sclerotherapy, shunt surgery, and staple transection of the oesophagus (haemostatic procedures) or liver transplantation (a procedure which solves both the problems of impaired liver function and of portal hypertension) should all be considered for this high risk group. No consensus seems to exist in the literature for the identification of risk factors having the best prognostic value for early mortality after variceal haemorrhage.

Lack of rigorous endoscopic criteria defining variceal haemorrhage such as those described by Buset et $a l,{ }^{4}$ lack of standardisation for the time of entry, ${ }^{5}$ non-uniform management of the variceal haemorrhage during the whole study period, analysis of either the first or the recurrent episodes of haemorrhage and differences in patient sampling or variables recorded may all have a part in explaining the contradictions among some of the studies published on this matter. ${ }^{36-13}$ The aim of our study is to identify among subjects treated using the same endoscopic protocol - that is, urgent sclerotherapy, those dying within the first six weeks of their first variceal haemorrhage. In addition, we have observed that a well characterised group of patients do not benefit from endoscopic therapy.

\section{Methods}

\section{PATIENTS}

One hundred and twenty one patients with their first variceal bleeding episode between June 1983 and December 1988 were retrospectively studied. Nineteen patients were excluded. Insufficient data on survival (patients admitted only for the management of the acute bleeding) or incomplete medical records excluded seven patients; 12 other patients were not studied because of prehepatic portal hypertension (four), associated hepatocellular carcinoma or other neoplasms (seven), or previous shunting (one). Thus, 102 patients were finally included with a diagnosis of parenchymal cirrhosis confirmed by pertinent clinical, biochemical or histological data. All had oesophageal varices at endoscopy. Cirrhosis was of alcoholic origin in $62 \%$ of the cases and the distribution according to the ChildPugh classification was $23 \%, 45 \%$, and $32 \%$ respectively for classes $\mathrm{A}, \mathrm{B}$, and $\mathrm{C}$. A complete history was always obtained (with the family and the general practitioner if the patient was unable to collaborate); physical examination and laboratory analysis were performed at time zero of the index bleed. Emergency oesophagogastroduodenoscopy was done in all cases within 12 hours of the index bleed. Time zero is the time of 
admission to the first hospital. If the patient was already in the hospital, it was the time when haematemesis or melaena occurred.

When admitted to our hospital, all patients were managed by fluid resuscitation (intravenous infusion of colloids to achieve haemodynamic stabilisation or a systolic blood pressure above $90 \mathrm{~mm} \mathrm{Hg}$ ) followed by endoscopy and mixed intravariceal and paravariceal injection sclerotherapy. Polidocanol 1\% (Aethoxysclerol) was most frequently used (97 of 102 patients); recently, isobutyl-2-cyanoacrylate (Bucrylate) was used in a case of profuse oesophageal variceal haemorrhage or in a case of bleeding caused by gastric varices (five of 102 patients). Follow up sclerotherapy was always done after 48 hours unless recurrent bleeding occurred earlier and then at one to two weeks' interval during the same hospital stay. Balloon tamponade (Linton tube) and vasoactive drugs (vasopressin) were used for haemorrhage which persisted despite sclerotherapy (four cases). After this first study, the resulting model of prediction of outcome at six weeks was validated on the next 28 patients admitted between January 1989 and May 1990 with their initial variceal bleed. The same criteria defined above were used to select this population.

\section{VARIABLES}

Twenty five variables (12 qualitative and 13 quantitative) related to clinical or biological data, endoscopic features or to the importance of the haemorrhage were collected at admission and for the next 72 hours for transfusions. The qualitative variables were: sex, aetiology of cirrhosis (alcholic or non-alcholic), activity of alcoholism (active consumption at time zero, abstinence for at least one month or undetermined status), duration of liver disease from the initial diagnosis ( $<$ two years, two to five years, $>$ five years), degree of ascites (absent, moderate, severe), degree of encephalopathy (absent, moderate, coma) a defined by Adam and Foley, ${ }^{14}$ extrahepatic infection (pulmonary, urinary, or ascitic: present or not), previous non-surgical haemostatic procedures before admission if referred from other hospitals (vasoactive drugs, tamponade) yes or no, source of variceal bleeding: oesophageal, gastric type $1,2,3^{15}$ or by exclusion of any other potential site of bleeding, activity of parenchymal cirrhosis (29 deaths; specific mortality caused by liver failure or exsanguination, other is represented by infections and deaths of unknown origin).

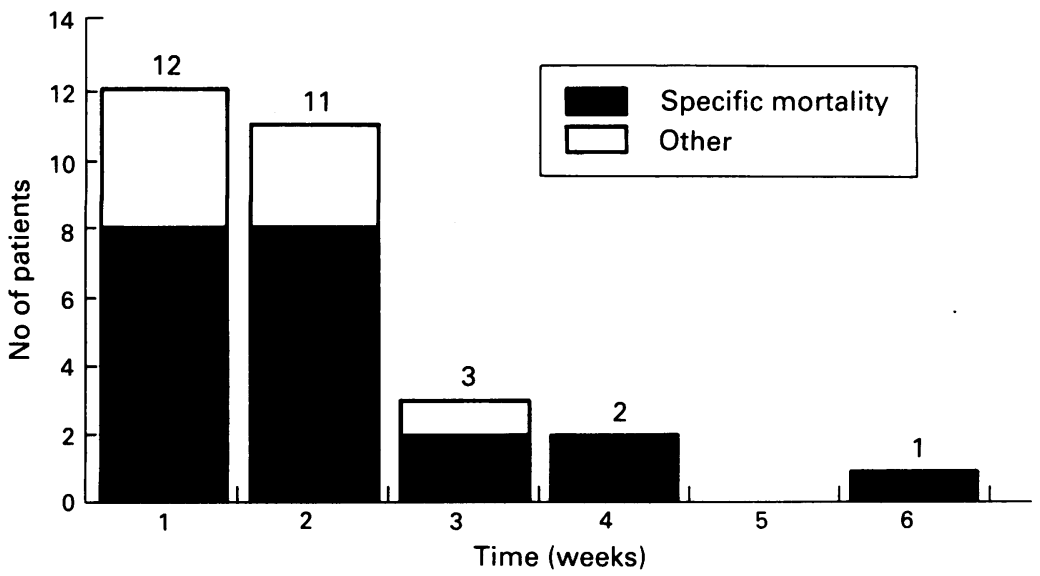

the bleeding: active (spurting or oozing) or recent (platelet aggregate, adherent clot), ${ }^{+}$staging of oesophageal varices $(1 \text { and } 2,3,4)^{16}$ and the presence of blood in the stomach (yes or no). The quantitative variables were: age (years), systolic blood pressure ( $\mathrm{mm} \mathrm{Hg}$ ), heart rate (beats/min), haemoglobin (g/dl), albumin (g/l), prothrombin time (\%), aspartate aminotransferase, IU/l, alanine aminotransferase, IU/1, bilirubin $(\mu \mathrm{mol} /$ 1), the number of blood units transfused within 72 hours of admission (to restore vital signs aiming for a haemoglobin level of $9 \mathrm{~g} / \mathrm{dl}$ ); the amount of polidocanol injected per patient during the first sclerotherapy session $(\mathrm{ml})$, Child-Pugh score, ${ }^{17}$ and serum creatinin $(\mu \mathrm{mol} / \mathrm{l})$.

\section{STATISTICAL ANALYSIS}

Survival curves were analysed using the actuarial method of Mantel-Haenzel. ${ }^{18}$ Aiming to identify the patients dying specifically from their liver disease and to avoid biases by time dependent variables (blood transfusion requirements within the 72 hours), statistical analysis was performed on the 91 patients still alive after 72 hours and after exclusion of the patients dying from other causes than liver failure or exsanguination $(\mathrm{n}=8)$. Two stepwise logistic regression procedures were performed. ${ }^{19}$ The first using the Pugh score alone as independant variable (Pugh model) and, the second, including all variables (Pugh excluded) achieving a statistical significance of $\mathrm{p}<0 \cdot 1$ in univariate analysis using $\chi^{2}$ tests (current model). Variables were entered into or removed from the logistic regression equation one at a time. Preassigned $p$ values equal to $0 \cdot 10$ and 0.15 controlled the stepping of entry and removal respectively. Missing data were not considered in the analysis. Regression coefficients and their standard error were calculated with a CYBER 855 computer for those variables which entered and remained in the regression equation. From this equation, histograms of predicted probabilities of success were computed for each individual belonging either to the successes group (alive at six weeks) or to the failures group (dead at six weeks). From these histograms, a probability cut off point could be selected to maximise the proportions of correctly predicted successes and failures. The two models were compared in terms of efficiency in predicting outcome at six weeks (probability of correct classification), in terms of goodness to fit and accuracy of adjustment of the data to the models and finally using receiver operating characteristic curves. ${ }^{20}$

\section{Results}

Among the 102 patients with parenchymal cirrhosis, 42 died from time zero to 12 months after their first variceal haemorrhage. Most of the deaths (29/42) occurred within the first six weeks of the index bleed. Six weeks mortality was thus $28 \%(29 / 102)$ and one year mortality $40 \%(42 /$ 102). Figure 1 shows the distribution and the causes of deaths within the six weeks: exsanguination was the cause of death in 15 patients (pure exsanguination without signs of liver failure 


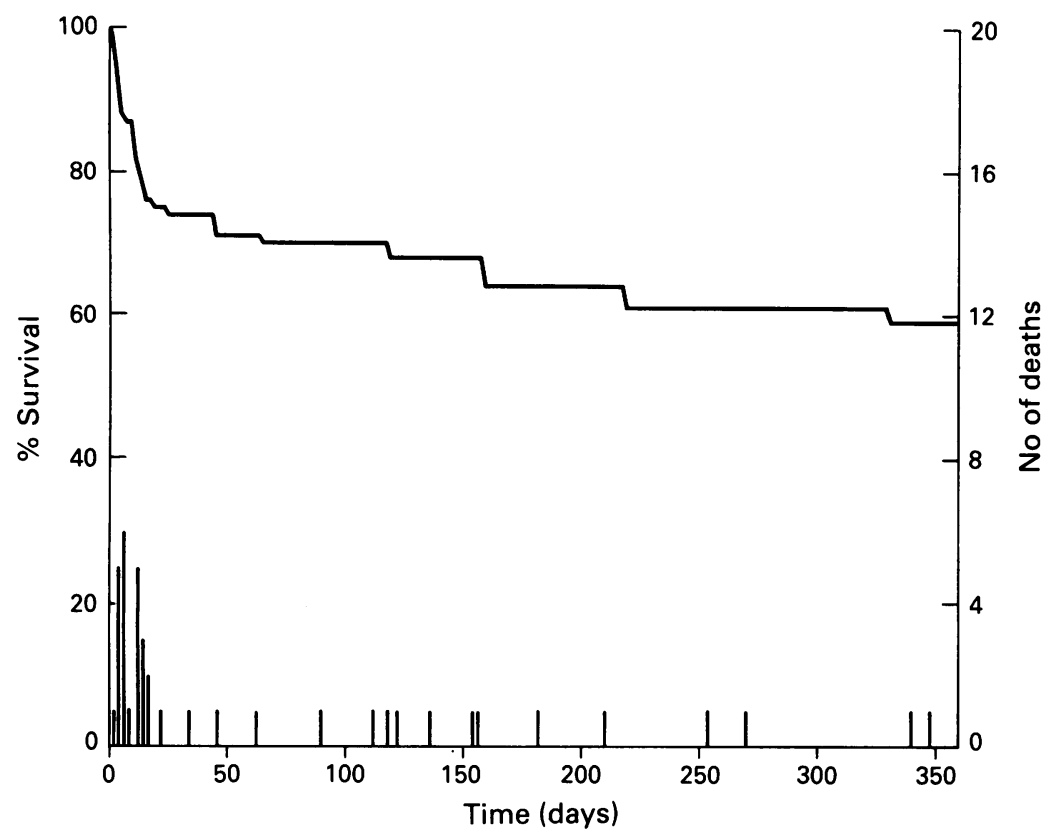

Figure 2: Percentage of survival and number of deaths plotted as function of time in 102 cirrhotic patients presenting with their first variceal haemorrhage. sion coefficients to include in the logistic equation and their significance are depicted in Table III. For each patient, $\mathrm{p}$ was calculated according to the value of each variable and its respective regression coefficient. For both groups, observed successes (alive at six weeks) and failures (dead at six weeks) were analysed. Using a 0.7 probability cut off point below which the patient is predicted to die and above which he is predicted to survive at six weeks yields correct classification in $97 \%(71 / 73)$ of surviving patients, $89 \%(16 / 18)$ of deaths and $96 \%(87 / 91)$ of both survival and deaths when assessing specific outcome with the current model. Using the same cut off point yields a correct classification of $90 \%(66 / 73)$ of surviving patients, $67 \%$ $(12 / 18)$ of deaths and $86 \%(78 / 91)$ of both survivals and deaths when assessing specific outcome with the Pugh model. In terms of goodness of fit and accuracy of adjustment, specific outcome was also significantly better predicted with our model compared to the Pugh model: $1.0 v 0.7$, from -45.278 to $-16.072 v$ from $-45 \cdot 278$ to $-28 \cdot 881$, respectively, for a cut point of $0.7(p<0.05)$. Furthermore, as seen in Figure 3 , the receiver operating characteristic curve of our model reveals a greater area under the curve than the one of the Pugh score, unknown in the others)). Specific mortality related to the liver disease and including death by exsanguination, liver failure or both therefore affects 21 patients among whom three died during the first 72 hours. The patient survival curve is represented in Figure 2. There is a rapid and immediate increase in the risk of dying shortly after the index bleed. Univariate analysis of qualitative and quantitative data are represented respectively in Table I and Table II. Two of the 12 qualitative and seven of the 13 quantitative variables which were studied in univariate analysis significantly influenced patient's survival at six weeks. As many of those variables were obviously correlated with each other, their study according to multivariate methods was mandatory. Three of those eight variables (excluding Pugh score) independently influenced patient survival in the logistic regression analysis: encephalopathy, Prothrombin time and units of blood transfused within the first 72 hours (current model).

The logistic equation which allows us to calculate the $p$ value is:

$$
\mathrm{p}=\frac{\mathrm{e}^{\mathrm{a}}}{\left(\mathrm{e}^{\mathrm{a}}+1\right)}
$$

$\mathrm{p}=$ probability of dying or of living at six weeks.

$\mathrm{e}=2 \cdot 7183$ (base of the natural logarithm)

$\mathrm{a}=-2.75 \times(\mathrm{ENC})+0.10 \times(\mathrm{PT})-0.31(\mathrm{BU})+$ $2 \cdot 64$

ENC (encephalopathy) $=1$ (absent)

$$
\begin{aligned}
& 2 \text { (moderate) } \\
& 3 \text { (coma) }
\end{aligned}
$$

PT $($ Prothrombin time $)=$ absolute value in $\%$ $\mathrm{BU}=$ number of blood units transfused within 72 hours after time zero.

The same procedure was then applied using only the Pugh score as independent variable to predict outcome at six weeks (Pugh model). Variables, the constants, their respective regres-

\begin{tabular}{|c|c|c|c|}
\hline Variables & $\begin{array}{l}\text { Patients } \\
\text { (alive) }\end{array}$ & $\begin{array}{l}\text { Patients } \\
\text { (dead) }\end{array}$ & Significance \\
\hline $\begin{array}{l}\operatorname{Sex}(M / F) \\
\text { Aetiology (alc/non-alc) }\end{array}$ & $\begin{array}{l}50 / 23 \\
43 / 30\end{array}$ & $\begin{array}{l}8 / 10 \\
12 / 6\end{array}$ & $\begin{array}{l}\text { NS } \\
\text { NS }\end{array}$ \\
\hline $\begin{array}{l}\text { Activity of alcoholism } \\
\text { (act/non-act/undet.) }\end{array}$ & $31 / 7 / 4$ & $18 / 2 / 1$ & NS \\
\hline Duration of disease $(\mathrm{yr})$ : & & & \\
\hline $\begin{array}{l}<2 \\
2-5 \\
>5\end{array}$ & $\begin{array}{l}4 \\
27 \\
42\end{array}$ & $\begin{array}{l}1 \\
8 \\
9\end{array}$ & NS \\
\hline Ascites: & & & \\
\hline $\begin{array}{l}\text { Absent } \\
\text { Moderate }\end{array}$ & $\begin{array}{l}39 \\
26\end{array}$ & $\begin{array}{l}8 \\
7\end{array}$ & NS \\
\hline $\begin{array}{l}\text { Severe } \\
\text { Encephalopathy: }\end{array}$ & 8 & 3 & \\
\hline $\begin{array}{l}\text { Absent } \\
\text { Moderate }\end{array}$ & $\begin{array}{l}62 \\
11\end{array}$ & $\begin{array}{r}2 \\
12\end{array}$ & $\mathbf{p}<0.0001$ \\
\hline $\begin{array}{l}\text { Severe } \\
\text { Infection }(\mathrm{Y} / \mathrm{N})\end{array}$ & & 4 & \\
\hline Previous haemostatic & 9/64 & $1 / 11$ & $p<0 \cdot 0\rangle$ \\
\hline $\begin{array}{l}\text { procedures }(\mathrm{Y} / \mathrm{N}) \\
\text { Source of bleeding }\end{array}$ & $10 / 63$ & $1 / 17$ & NS \\
\hline (Oes/Gas/Excl) & $46 / 16 / 11$ & $11 / 6 / 1$ & NS \\
\hline $\begin{array}{l}\text { Activity of bleeding } \\
\text { (Act/Rec) }\end{array}$ & $19 / 42$ & $12 / 7$ & NS \\
\hline $\begin{array}{l}\text { Staging of varices: } \\
\text { I \& II } \\
\text { III } \\
\text { IV }\end{array}$ & $\begin{array}{r}9 \\
38 \\
26\end{array}$ & $\begin{array}{r}2 \\
14 \\
2\end{array}$ & NS \\
\hline Blood in stomach $(\mathrm{Y} / \mathrm{N})$ & $62 / 11$ & $17 / 1$ & NS \\
\hline
\end{tabular}

TABLE I Prognostic factors influencing survival at six weeks univariate study: qualitative data

\begin{tabular}{|c|c|c|c|}
\hline Variables & Alive & Dead & Significance \\
\hline Age (yr) & $56(13)$ & $58(9)$ & \\
\hline pressure $(\mathrm{mm} \mathrm{Hg})$ & $113(23)$ & $106(21)$ & $p=0.04$ \\
\hline Heart rate (beats $/ \mathrm{min}$ ) & $108(14)$ & $117(22)$ & $\mathrm{p}=0.04$ \\
\hline Haemoglobin (gr/dl) & $8.9(2 \cdot 1)$ & $8 \cdot 9(2 \cdot 1)$ & NS \\
\hline Albumin $(g / l)$ & $34(6)$ & $31(4)$ & \\
\hline Prothrombin time (\%) & $59(14)$ & $36(15)$ & $p=0.06$ \\
\hline $\operatorname{AST}(\mathrm{IU} / \mathrm{l})$ & $54(46)$ & $225(567)$ & $\mathrm{p}=0.01$ \\
\hline ALT (IU/I) & $36(27)$ & $134(342)$ & $\mathrm{p}=0.02$ \\
\hline Bilirubin $(\mu \mathrm{mol} / \mathrm{l})$ & $49(54)$ & $119(95)$ & $\mathrm{p}=0.01$ \\
\hline Blood transfused (units) & $3.6(2.9)$ & $8.6(8)$ & $\mathrm{p}=0.005$ \\
\hline canol (ml) & $15(19)$ & $31(28)$ & NS \\
\hline & & $11(2)$ & $\mathrm{p}<0.0001$ \\
\hline & $106(62)$ & $150(79)$ & \\
\hline
\end{tabular}

TABLE II Prognostic factors influencing survival at six weeks univariate study: qualitative data (mean $(S D)$ )

AST $=$ aspartate aminotransferase $; \mathrm{ALT}=$ alanine aminotransferase. 
TABLE III Results of the logistic regressions. Comparison between the Pugh model and the current model

\begin{tabular}{lclcl}
\hline & Constant & Variables & $\begin{array}{l}\text { Regression coefficients } \\
\text { (standard error) }\end{array}$ & Significance \\
\hline Pugh model & 10.267 & Pugh score & $-0.926(0.222)$ & $\mathrm{p}<0.005$ \\
Current model & 2.640 & Encephalopathy & $-2.748(0.962)$ & $\mathrm{p}<0.01$ \\
& & Prothrombin time & $0.102(0.037)$ & $\mathrm{p}<0.01$ \\
& & Blood units transfused & $-0.310(0.120)$ & $\mathrm{p}<0.05$ \\
\hline
\end{tabular}

therefore confering a better specificity and sensitivity to our model. Analysing the predictive value of the logistic regression with our three variables, there was no statistical difference between alcoholic and non-alcoholic patients (data not shown). The validation of our model using the same selection criteria was also mandatory. We have calculated the $\mathrm{p}$ value for each patient (28) admitted in the next period of the study using the grade of encephalopathy, ${ }^{1-3}$ the absolute value of prothrombin time at the admission and the number of blood units transfused within the $\mathbf{7 2}$ hours after admission. Results are shown in Figure 4 confirming the effectiveness of our model: $82 \%$ (nine of 11 ) of the deaths and $94 \%$ (16 of 17) of the patients still alive at six weeks could be predicted.

\section{Discussion}

This study shows that using a prognostic equation containing only three variables: encephalopathy, prothrombin time, and the number of blood units transfused within 72 hours, specific outcome (survival or death as a result of liver failure or exsanguination) within six weeks of the

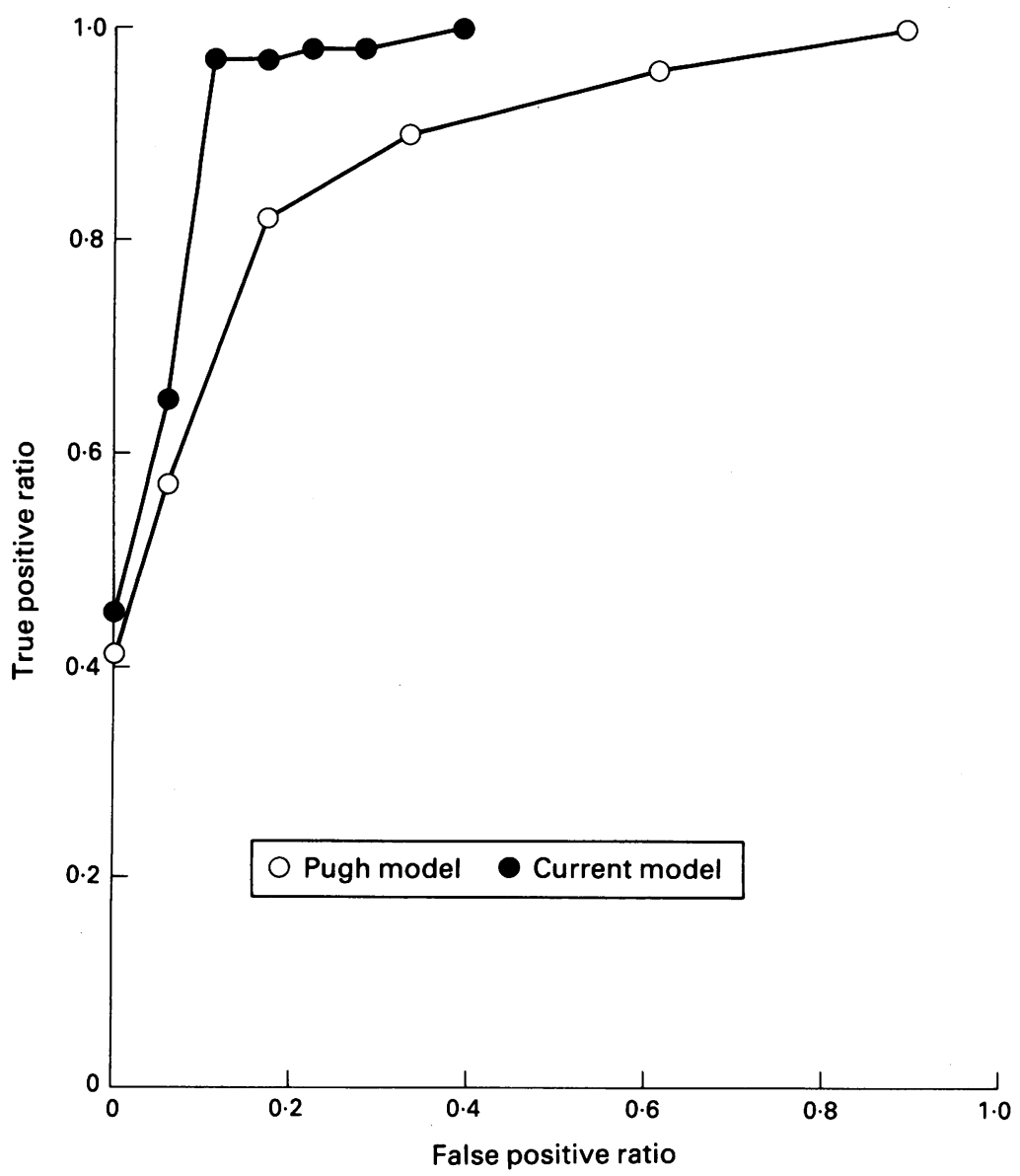

Figure 3: Receiver operating characteristic curves: true positive ratio and false positive ratio for different cut off points of the Pugh and the current models. first variceal haemorrhage of cirrhotic patients could be predicted in at least $89 \%$ of the cases. Several other studies focusing on variceal bleeding prognosis have been published. ${ }^{36-12}$ Conclusions are often discordant, however, and the predictive value of the results is often difficult to assess from the data. Several explanations for these discrepancies can be offered. First, the absence of rigorous endoscopic criteria for defining variceal haemorrhage or indications for sclerotherapy could be two explanations for the discrepancies. In our study, the source of bleeding (oesophagus or stomach) and the activity of bleeding (active or recent) were defined according criteria previously described. ${ }^{+}$During the whole study period the same strict policy was adopted: patients underwent endoscopy at admission as soon as they were haemodynamically stable and emergency sclerotherapy was initiated as a primary therapy in case of active or recent variceal bleeding using either polidocanol or more recently cyanoacrylate. Conclusions regarding cyanocrylate are not yet available because of the limited experience at present. A recent report, however, shows promising results with cyanoacrylate in cases of gastric variceal bleeding. ${ }^{21}$ Second, absence of standardisation of the time of entry could be another explanation for the discrepancies between the results of various authors. As emphasised by Burroughs et $a l,{ }^{5}$ changing the starting point for analysis after variceal haemorrhage leads to completely different conclusions. In our study the clinical and biological variables were obtained as close to the index bleed as possible, if necessary by consulting the medical charts of the referring hospital. Third, analysis of the first bleeding episode was only done by Christensen, " Cales, ${ }^{22}$ and Garcia Pagan. ${ }^{13}$

It is very important to distinguish the first from the subsequent bleeding episodes because associated mortality is different and this may lead to biases in studies when pooling the two types of episodes. ${ }^{10}$ Unfortunately these three studies $^{11322}$ also suffer from other shortcomings. Indeed, in the first series of patients only $72 \%$ were bleeding from varices, haemostatic treatment was not uniform and only a minority were treated with sclerotherapy. In the second series only 30 patients with variceal bleeding were considered and the treatment was not defined. In the third series, sclerotherapy was not done as the initial treatment. ${ }^{13}$ Finally, differences in patient sampling (percentage of alcoholics, percentage of Child-Pugh C cirrhotic patients) or in variables recorded could also explain the discrepancies. Our work emphasises the prognostic value of three variables: encephalopathy, prothrombin time, and the number' of blood units transfused within the 72 hours after time zero. The first two are related to residual liver function and the last to the importance of the haemorrhage. These findings are compatible with other observations on the prognostic value of high grade encephalopathy, ${ }^{1123}$ and low prothrombin index..$^{23-25}$ The fact that only two variables of the Pugh score are so powerful in our model is probably related to two reasons: first, in case of variceal haemorrhage, some of the five variables of this score are probably redundant 


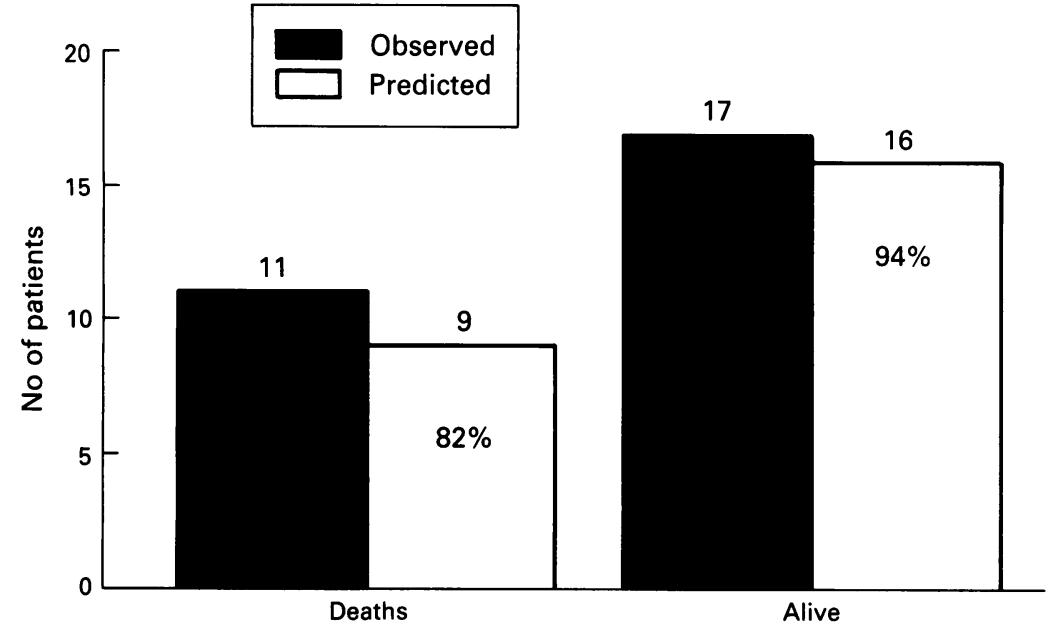

Figure 4: Prospective study ( $n=28$ patients). Comparison of observed and predicted outcome at six weeks using the current model. transplantation and the decision to proceed to transplantation should be considered in the high risk group defined by us.

We wish to thank Mrs Viviane Tonus and Mrs Mia Persoons for typing this manuscript and Dr Ghattas for helpful discussions.

1 Burroughs AK, D'Heygere F, McIntyre N. Pitfalls in studies of prophylactic therapy for variceal bleeding in cirrhotics. Hepatology 1986; 6: 1407-13.

2 Witzel L, Wolbergs E, Merki H. Prophylactic endoscopic sclerotherapy of oesophageal varices. A prospective controlled study. Lancet 1985; i: 773-5.

3 Graham DY, Smith L. The course of patients after variceal haemorrhage. Gastroenterology 1981; 80: 800-9.

4 Buset M, Desmarez B, Baize M, Bourgeois N, Cremer M Bleeding oesophagogastric varices: an endoscopic study. Am $\mathcal{F}$ Gastroenterol 1987; 82: 241-4.

5 Burroughs AK, Mezzanotte G, Phillips A, McCormick PA McIntyre N. Cirrhotics with variceal haemorrhage: the importance of the time interval between admission and the start of rate analysis for survival and rebleeding. Hepatology 1989; 9: 801-7.

6 Poynard T, Chaput JC, Mary JY, Scolaro M, Buffet C Etienne JP. Analyse critique des facteurs liés à la mortalite au trentième jour dans les hémorragies digestives hautes $\mathrm{du}$ cirrhotique. Gastroenterol Clin Biol 1980; 4: 655-65.

7 Garden OJ, Motyl H, Gilmour WH, Utley RJ, Carter DC Prediction of outcome following acute variceal haemorrhage. BrF Surg 1985; 72: 91-5.

8 Prindiville T, Miller M, Trudeau W. Prognostic indicators in acute variceal hemorrhage after treatment by sclerotherapy. Am $\mathcal{F}$ Surgery 1987; 82:655-9.

9 Melchior JC, Poupon RE, Verrier J, Merrer J, Moncorge C Simon N. Analyse des facteurs liés à la mortalité précoce au cours des hémorragies digestives dues à l'hypertension portale. Gastroenterol Clin Biol 1987; 11: 402-8.

10 Cales P, Pascal JP. Histoire naturelle des varices oesophagiennes au cours de la cirrhose. Gastroenterol Clin Biol 1988 12: $245-54$.

11 Christensen E, Krinten JJ, Meltofte Hansen S, Krogh Johansen J, Juhl E. Prognosis after the first episode of gastrointestinal bleeding or coma in cirrhosis. Scand $\mathcal{f}$ Gastroenterol 1989; 24: 999-1006.

12 Burroughs AK, Hamilton G, Phillips A, Mezzanotte G, McIntyre N, Wobbs KEF. A comparison of sclerotherapy with staple transection of the oesophagus for the emergency with staple transection of the oesophagus for the emergency control of bleeding

13 Garcia Pagan JC, Teres J, Calvet X, Bosch J, Rodes J. Factors which influence the prognosis of the first episode of variceal haemorrhage in patients with cirrhosis. In: Bosch J, Rodes J, eds. Recent advances in the pathophysiology and therapy of portal hypertension. Barcelona. Ares Seronsoymposia Review, 1990: 287-301.

14 Adams RS, Foley JM. Neurological changes in more common types of severe liver disease. Trans Am Neurol Assoc 1949; 74: $217-9$.

15 Hosking SW, Johnson AG. Gastric varices: a proposed classification to management. BrF Surg 1988; 75: 195-6.

16 Paquet KJ. Prophylactic endoscopic sclerosing treatment of the oesophageal wall in varices. A prospective controlled trial. Endoscopy 1982; 14: 4-5.

17 Pugh RNH, Murray-Lyon IM, Dawson JL, Pietroni MC, Williams R. Transection of the oesophagus for bleeding oesophageal varices. $B r \mathcal{F}$ Surgery 1973; 60: 646-9.

18 Mantel N. Evaluation of survival data and two rank order statistics arising in its consideration. Cancer Chemother Resp 1966; 50: 163-70.

19 Dixon WJ, ed. BMDP Statistical software. Berkeley: University of California Press, 1983: 330-4.

20 McNeil BJ, Keeler E, Adelstein J. Primer on certain elements of medical decision making. N Engl F Med 1975; 293: 211-5.

21 Ramond MJ, Valla D, Mosnier JF, Degott C, Bernuau J, Rueff $\mathrm{B}$, et al. Successful endoscopic obturation of gastric varices with butyl cyanoacrylate. Hepatology 1989; 10: 48893.

22 Cales $\mathrm{P}$, et groupe d'étude de la prophylaxie primaire. Facteur prédictifs de la première hémorragie digestive et de la mortalité chez les malades cirrhotiques avec varices oesophagiennes. Gastroenterol Clin Biol 1989; 13: 54-9.

23 Orrego $\mathrm{H}$, Israel Y, Blake JE, et al. Assessment of prognostic factors in alcoholic liver disease: toward a global quantitative expression of severity. Hepatology 1983; 3: 896-905.

24 Sauerbruch T, Weinzierl M, Kopcke W, et al. Long term sclerotherapy of bleeding oesophageal varices in patients with liver cirrhosis. An evaluation of mortality and rebleeding risk factors. Scand $\mathcal{F}$ Gastroenterol 1985; 20: 51-8.

25 Gines $P$, Quintero E, Arroyo V, et al Compensated cirrhosis: natural history and prognostic factors. Hepatology 1987; 7: natural

26 Bernuau J. Traitemeni de l'hypovolémie après une hémorragie digestive haute par hypertension portale au cours de la cirrhose. Gastroenterol Clin Biol 1990; 14: 25-8B.

27 The Copenhagen Oesophageal varices sclerotherapy project. Sclerotherapy after first variceal haemorrhage in cirrhosis. NEnglF Med 1984; 311: 1594-600.

28 Moller S, Sorensen TIA, Tygstrup N, and the EVASP group. Early identification of patients with bleeding oesophagea varices treatable by sclerotherapy [Abstract]. 7 Hepato 1989; 51 (suppl 9): 66.

29 Stiegmann GV, Goff JS, Jun JH, Davis D, Bozdech J. Endoscopic variceal ligation: an alternative to sclerotherapy. Gastrointest Endosc 1989; 35: $431-4$. jected to changes after improvement of the patient's status) cirrhotic patients with their first, potentially lethal, variceal bleeding should be early stratified as candidates or not for liver 